\title{
Vestibular modulation of postural stability: An update.
}

\author{
Sahaya Rani ${ }^{*}$, Archana $\mathbf{R}^{2}$, Shyla Kamala Kumari ${ }^{3}$ \\ ${ }^{1}$ St. Mary's School of Nursing, Coimbatore, Tamil Nadu, India \\ ${ }^{2}$ Department of Physiology, Saveetha Institute of Medical and Technical Science, Saveetha University, Chennai, Tamil \\ Nadu, India \\ ${ }^{3}$ Sree Abhirami College of Nursing, Coimbatore, Tamil Nadu, India
}

\begin{abstract}
Postural stability is defined as the dynamic postural response to applied perturbations. Postural stability is an important topic of discussion especially for older people. Because as there is increase in the age the integration between different body systems will decrease and this may contribute for balance difficulties. Balance difficulties were one of the major factors that decrease the quality of life in elderly people. Physical activity was reported to increase the strength of the muscles and limit the fall and faints due to postural disturbances. The vestibular stimulation regulates postural control through influencing integration in all levels that is cortical, midbrain, medulla and spinal cord levels. The present article provides an understanding of vestibular modulation of postural stability through influencing the integration of neural signals at different levels. This understanding helps to plan the management techniques accordingly and it is the need of time to conduct more studies in this area to recommend vestibular stimulation as an adjunctive therapy for management of postural instabilities.
\end{abstract}

Keywords: Postural stability, Vestibular stimulation, Physical activity.

Accepted on September 22, 2018

\section{Introduction}

Postural stability is defined as the dynamic postural response to applied perturbations [1]. Postural stability is an important topic of discussion especially for older people. Because as there is increase in the age the integration between different body systems will decrease and this may contribute for balance difficulties. Balance difficulties were one of the major factors that decrease the quality of life in elderly people [2-4]. Physical activity was reported to increase the strength of the muscles and limit the fall and faints due to postural disturbances [5]. Vestibular system is the part of inner ear. It plays a major role in the maintenance of posture and equilibrium through statokinetic reflexes [6]. It has two vestibular organs called otolithic organs and semicircular canals. Linear acceleration and deceleration was detected by otolithic organs whereas angular acceleration and deceleration was detected by semicircular canals. Earlier studies reported that stimulating the vestibular system has positive impact in the elderly population suffering with postural difficulties $[7,8]$. In fact most of the exercise designed for improving the postural stability stimulates vestibular system. Postural instability was commonly observed in patients with vestibular damage [9]. Galvanic vestibular stimulation was reported to be beneficial to modulate postural instability in individuals with altered vestibular input [9]. Rocking is a simple way to stimulate vestibular system especially for elderly population [10]. The vestibular stimulation regulates postural control through influencing integration in all levels that is cortical, midbrain, medulla and spinal cord levels. The present article reviews the possible mechanisms of vestibular modulation of postural stability.

\section{Methods}

Review of the articles published from http:// www.google.com,http://www.pubmed.com, Medline, http:// www.frontiersin.org and other online journals was performed and analyzed.

\section{Role of Vestibular Stimulation in Cortical Integration}

There a number of studies where vestibular influences on the postural control was explained with experimental evidences in both healthy and disease conditions. The vestibular information will be integrated with the information from other sensory systems in the central nervous system $[11,12]$. Alteration in the integration of vestibular signals leads to the postural difficulties such as loss of coordination, vertigo etc. [13]. However, there are compensatory mechanisms in the central nervous system which balances any changes in the vestibular inputs. This is very important especially for sportsmen and pilots [14]. Vestibulo-ocular reflex plays a major role in this 
adaptation process [15-23]. Chronic stimulation of vestibular stimulation leads to the mechanism called vestibular habituation. Hence, the individuals can develop the ability to suppress the vestibular illusions. This was evident as trained pilots and trained sportsmen have better postural control than control group individuals [24].

\section{Role of Vestibular Stimulation in Midbrain Integration}

The structures of the midbrain include tectum which is made up of superior and inferior colliculus, tegmentum which consists of red nucleus, periaquiductal gray matter and substansianigra. Midbrain also comprises of crus cerebri and portion of reticular formation. The nuclear complex present in the midbrain are occulo motor nerve and trochlear nerve [25]. The superior collicus consists of seven layers of fibrous and cellular lamine. The superficial layers respond to visual stimuli whereas the deeper layers respond to sensory stimuli. Hence, the superior colliculs plays an important role in sensori motor transformations [26-29]. Spike potentials are recorded in the superior colliculus followed by stimulation of vestibular nerve [26]. Red nucleus is having projections to the cerebellum and spinal cord and plays a major role in the regulation of the motor control of the limbs along with the primary motor cortex [30]. It was reported that the superior vestibular nucleus can modify the activity of the cerebellorubral and corticorubral pathways, exerting inhibitory action on the neurons of the red nucleus [31].Periaqueductal gray matter plays an important role in the regulation of the movements of neck, back and hindlimbs [32]. Vestibular projections are identified in the midbrain structures like inferior colliculus, red nucleus and periaqueductal gray matter and interstitial nucleus of Cajal. These structures are reported to receive maximum number of projections from the vestibular system [33]. Vestibular stimulation results in activation of brain with higher amplitude which was reported to be essential for postural control [34].

\section{Role of Vestibular Stimulation in Medullary Integration}

The medullary pyramids consist of the corticobulbar and cortico spinal tracts. The cortico spinal tract plays an important role in the maintenance of posture. The cortico spinal pathway is longest axonal pathway and mediates the impulses from the cerebellum, basal ganglia and thalamus [35,36]. Vestibular system modulates the activity of cortico spinal tract through its connections with cerebellum, basal ganglia and thalamus. Earlier studies testified the presence of vestibulocerebellar and cerebellovestibular pathways [37]. It was reported that vestibular stimulation causes activation of the neurons in the cerebellum [38]. Stochastic vestibular stimulation was reported to correct the postural difficulties in the patients with Parkinson's disease (PD) [39]. Further, vestibular dysfunction was reported to cause postural difficulties in the patients with PD and stimulation of vestibular afferents was reported to be an effective therapy for management of postural difficulties [40]. It was reported that, impaired integration of pedunculopontine nucleus cholinergic neurons and their thalamic efferent fibers play a role in postural control [41]. Vestibular connections to thalamus were well known and stimulation of vestibular system evokes thalamic potentials [41].

\section{Role of Vestibular Stimulation in Spinal Cord Integration}

Vestibulo spinal pathways supplies to intercostal and back muscles, as well as the extensors of the limbs and maintain the posture. There are two reflexes that are medial and lateral vestibule spinal pathways. The lateral and medial vestibule spinal pathways originate from lateral and medial vestibular nucleus respectively [42]. The peculiarity of vestibular outputs is its wider distribution than any other sensory system. The lateral vestibule spinal pathway influences the primary motor neurons of the spinal cord whereas the medical pathway travels through medial fasciculus and reticulo-spinal pathways [43].

\section{Conclusion}

The present article provides an understanding of vestibular modulation of postural stability through influencing the integration of neural signals at different levels. This understanding helps to plan the management techniques accordingly and it is the need of time to conduct more studies in this area to recommend vestibular stimulation as an adjunctive therapy for management of postural instabilities.

\section{References}

1. Prieto TE, Myklebust JB, Myklebust BM. Characterization and modeling of postural steadiness in the elderly: A review. IEEE Trans RehabilEng 1993; 1: 26-34.

2. Patel M, Fransson P, Magnusson M. Effects of ageing on adaptation during vibratory stimulation of the calf and neck muscles. Gerontology 2009; 55: 82-91.

3. Blaszczyk J, Michalski A. Ageing and postural stability. Stud Phys Cult Tourism 2006; 13: 11-14.

4. Kim B, Robinson C. Postural control and detection of slip/fall initiation in the elderly population. Ergonomics 2005; 48: 1065-1085.

5. Macaluso A, De Vito G. Muscle strength, power and adaptations to resistance training in older people. Eur $\mathrm{J}$ Appl Physiol 2004; 91: 450-472.

6. Badke MB, Miedaner JA, Shea TA, Grove CR, Pyle GM. Effects of vestibular and balance rehabilitation on sensory organization and dizziness handicap. Ann Otol Rhinol Laryngol 2005; 114: 48-54.

7. Badke M, Shea T, Miedaner J. Outcomes after rehabilitation for adults with balance dysfunction. Arch Phys Med Rehabil 2004; 85:227-233.

8. Wrisley DM, Stephens MJ, Mosley S. Learning effects of repetitive administrations of the sensory organization test 
in healthy young adults. Arch Phys Med Rehabil 2007; 88: 1049-1054.

9. MacDougall HG, Moore ST, Curthoys IS, Black FO. Modeling postural instability with galvanic vestibular stimulation. Exp Brain Res 2006; 172: 208-220.

10. Kumar SSG. Need of vestibular stimulation. J Clin Biomed Sci 2014; 4: 263-264.

11. Massion J. Postural control system. Curr Opin Neurobiol 1994; 4: 877-887.

12. Cenciarini M, Peterka RJ. Stimulus-dependent changes in the vestibular contribution to human postural control. J Neurophysiol 2006; 95: 2733-2750.

13. Clément G, Wood SJ. Rocking or rolling--perception of ambiguous motion after returning from space. PLoS One 2014; 9: e111107.

14. Deveze A, Bernard-Demanze L, Xavier F, Lavieille JP, Elziere M. Vestibular compensation and vestibular rehabilitation. Current concepts and new trends. Neurophysiol Clin 2014; 44: 49-57.

15. Deveze A, Bernard-Demanze L, Xavier F, Lavieille JP, Elziere M. Vestibular compensation and vestibular rehabilitation. Current concepts and new trends. Neurophysiol Clin 2014; 44: 49-57.

16. Tiliket C, Shelhamer M, Roberts D, Zee DS. Short-term vestibulo-ocular reflex adaptation in humans. I. Effect on the ocular motor velocity-to-position neural integrator. Exp Brain Res 1994; 100: 316-327.

17. Balter SG, Castelijns MH, Stokroos RJ, Kingma H. Galvanic-induced body sway in vestibular schwannoma patients: evidence for stimulation of the central vestibular system. Acta Otolaryngol 2004; 124: 1015-1021.

18. Fransson PA, Hjerpe M, Johansson R. Adaptation of multi-segmented body movements during vibratory proprioceptive and galvanic vestibular stimulation. J Vestib Res 2007; 17: 47-62.

19. Son GM, Blouin JS, Inglis JT. Short-duration galvanic vestibular stimulation evokes prolonged balance responses. J ApplPhysiol 2008; 105: 1210-1217.

20. Bonan IV, Marquer A, Eskiizmirliler S, Yelnik AP, Vidal PP. Sensory reweighting in controls and stroke patients. Clin Neurophysiol 2013; 124: 713-722.

21. Deshpande N, Patla AE. Visual-vestibular interaction during goal directed locomotion: Effects of aging and blurring vision. Exp Brain Res 2007; 176: 43-53.

22. Maitre J, Gasnier Y, Bru N, Jully JL, Paillard T. Discrepancy in the involution of the different neural loops with age. Eur J Appl Physiol 2013; 113: 1821-1831.

23. Eikema DJ, Hatzitaki V, Tzovaras D, Papaxanthis C. Application of intermittent galvanic vestibular stimulation reveals age-related constraints in the multisensory reweighting of posture. Neurosci Lett 2014; 561: 112-117.

24. Balter SGT, Stokroos RJ, Akkermans E, Kingma H. Habituation to galvanic vestibular stimulation for analysis of postural control abilities in gymnasts. NeurosciLett 2004; 366: 71-75.
25. Breedlove M, Watson NV, Rosenzweig MR. Biological Psychology (6th Edn) Sinauer Associates, USA, 2010.

26. Maeda M, Shibazaki T, Yoshida K. Labyrinthine and visual inputs to the superior colliculus neurons. Progress Brain Res 1979; 50: 735-743.

27. Hall WC, Moschovakis A. The superior colliculus: New approaches for studying sensorimotor integration. Boca Raton, FL: CRC Press; 2004.

28. Sparks DL, Mays LE. Signal transformations required for the generation of saccadic eye movements. Annu Rev Neurosci 1990; 13: 309-336.

29. Bolognini N, Leo F, Passamonti C, Stein BE, Làdavas E. Multisensory-mediated auditory localization. Perception 2007; 36: 1477-1485.

30. Herter TM, Takei T2, Munoz DP3, Scott SH4. Neurons in red nucleus and primary motor cortex exhibit similar responses to mechanical perturbations applied to the upper-limb during posture. Front Integr Neurosci 2015; 9: 29.

31. Halasi G, Bácskai T, Matesz C.Connections of the superior vestibular nucleus with the oculomotor and red nuclei in the rat: an electron microscopic study. Brain Res Bull 2005; 66: 532-535.

32. Koutsikou S, Watson TC, Crook JJ, Leith JL, Lawrenson CL, Apps R, Lumb BM. The periaqueductal gray orchestrates sensory and motor circuits at multiple levels of the neuraxis. J Neurosci 2015; 35: 14132-14147.

33. Bácskai T, Székely G, Matesz C. Ascending and descending projections of the lateral vestibular nucleus in the rat. Acta Biol Hung 2002; 53: 7-21.

34. Noohi F, Kinnaird C, DeDios Y, Kofman IS, Wood S, Bloomberg J, Mulavara A, Seidler R. Functional brain activation in response to a clinical vestibular test correlates with balance. Front Syst Neurosci 2017; 11: 11.

35. Sarnat HB. Do the corticospinal and corticobulbar tracts mediate functions in the human newborn? Can J Neurol Sci 1989; 16: 157-160.

36. Brody BA, Kinney HC, Kloman AS, Gilles FH. Sequence of central nervous system myelination in human infancy. I. An autopsy study of myelination. J Neuropathol Exp Neurol 1987; 46: 283-301.

37. Wilson VJ, Jones GM. The vestibular system and the cerebellum. Mammalian Vestibular Physiology 1979.

38. Favilla M, Ghelarducci B, Hill CD, Spyer KM. Vestibular inputs to the fastigial nucleus; Evidence of convergence of macular and ampullar inputs. Pflügers Archiv 1980; 384: 193-201.

39. Samoudi G, Jivegard M, Mulavara AP, Bergquist F. Effects of stochastic vestibular galvanic stimulation and LDOPA on balance and motor symptoms in patients with Parkinson's disease. Brain Stimul 2015; 8: 474-480.

40. Kataoka H, Okada Y, Kiriyama T, Kita Y, Nakamura J, Morioka S, Shomoto K, Ueno S. Can postural instability respond to galvanic vestibular stimulation in patients with Parkinson's disease? J Mov Disord 2016; 9: 40-43. 
41. Müller MLTM, Albin RL, Kotagal V, Koeppe RA, Scott PJH, Frey KA, Bohnen NI. Thalamic cholinergic innervation and postural sensory integration function in Parkinson's disease. Brain 2013; 136: 3282-3289.

42. Rea P. Essential Clinical Anatomy of the Nervous System. Sprnger, Berlin, 2015.

43. Keshner EA, Cohen H. Current concepts of the vestibular system reviewed: 1. The role of the vestibulospinal system in postural control. Am J Occupat Ther 1989; 43: 320-330.

\section{${ }^{*}$ Correspondence to}

Sahaya Rani

St. Mary's School of Nursing

India 